\title{
Innovative technologies and equipment from „Amazone" company for fertilizer application
}

\author{
Viktor Buxmann ${ }^{1,}$, Besarion Meskhi $^{2}$, Andrey Mozgovoy ${ }^{2}$, Dmitry Rudoy ${ }^{2}$, and Anastasiya \\ Olshevskaya $^{2}$ \\ ${ }^{1}$ Amazonen-Werke H. Dreyer GmbH \& Co. KG, 49205, Osnabrueck, Germany \\ ${ }^{2}$ Don State Technical University, 344003, Gagarin sq., 1, Rostov-on-Don, Russia
}

\begin{abstract}
The development of new technologies and a complex of machines for applying mineral and liquid fertilizers is going on more and more intensively. Due to the warming climate, more frequent years with arid conditions during the ripening period of plants, the requirements for the complex of machines for applying fertilizers are changing. "Amazonen-Werke“ or „AMAZONE“ is a pioneer in precision farming, differentiated fertilization with the use of automation, electronics and telematics systems in agriculture. The article presents materials of new technical solutions for the introduction of both granular and liquid fertilizers. Especially the development and research of new machines in the arid regions of Russia, allow you to find the optimal solution in the application of liquid fertilizers.
\end{abstract}

\section{Introduction}

In western Europe, fertilizers are mainly applied in granular form. This is due to the presence of sufficient moisture and the ability to apply fertilizers in a scattered way from 3 to 5 times during the growing season.

In Russia, the presence of many natural and climatic zones, many regions with an arid climate and a lack of moisture during the growing season, as well as significant fluctuations in precipitation from year to year, forces the use of various fertilization technologies. And not only granular, but more and more active liquid fertilizers. Moreover, the application technologies are diverse: a) granular - by scattering on the soil surface and by subsoil methods during sowing or tillage and b) liquid - into the soil superficially and subsoil - on plants as foliar feeding. [1-3]

To implement these fertilization technologies, the „Amazonen-Werke“ company developed and manufactured various modern machines. To determine their effectiveness, the company conducts tests in real conditions with a number of agricultural universities in Russia. For many years, such research and testing has been carried out with the Samara SAU, Barnaul SAU and Kuban SAU. Also, research related to telematics, digitalization, new design devices and the development of control programs for agricultural machinery, automation of machine operation processes [1].

*Corresponding author: Dr.Viktor.Buxmann@amazone.de 
The article describes materials of modern technologies and efficient machines for the differentiated application of mineral and liquid fertilizers, specially developed by a German company „AMAZONE“. Both spreaders and liquid fertilizer applicators supplied either by factories „AMAZONE“ from Germany, or subsidiary plant "Eurotechnika" (Samara) in Russia. Research was carried out in agricultural enterprises of the Samara region and the Altai Region. For efficient agrochemical maintenance of crops in agriculture, the company produces special spreaders of solid mineral fertilizers, in particular the ZA - TS 3200 spreader (Fig. 1a), which is equipped with a new TS spreading device [2, p. 10-14].

a)

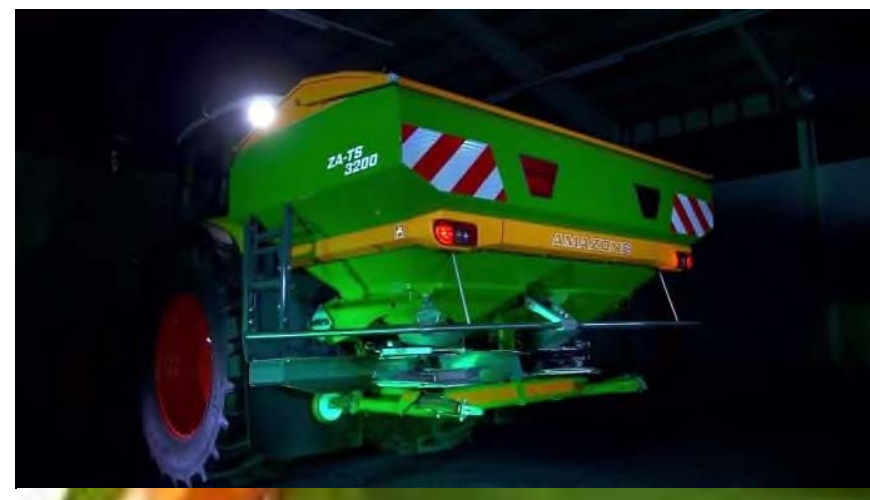

b)

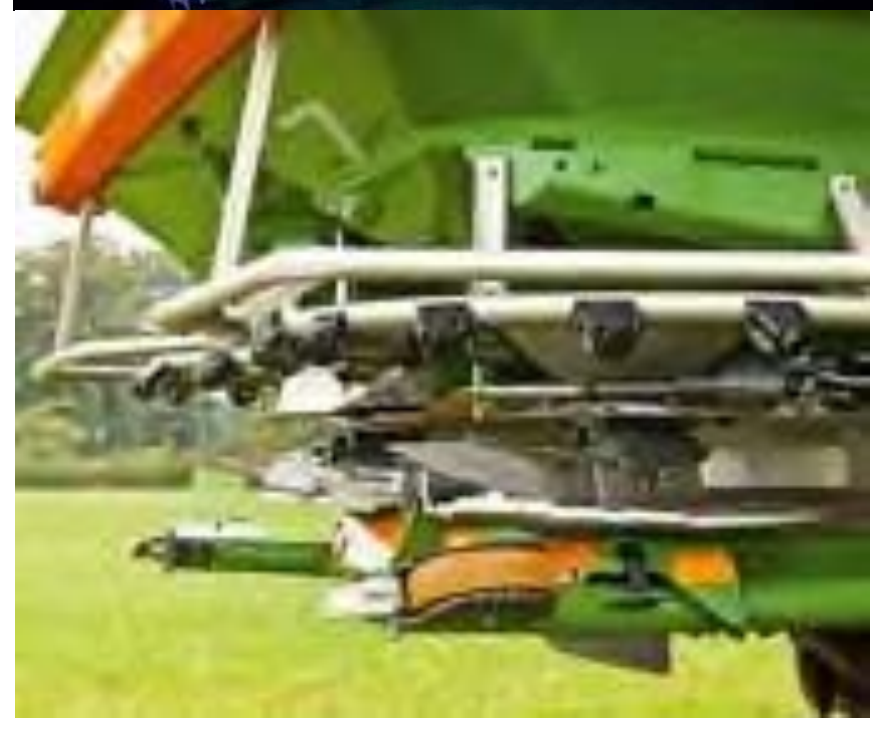

Fig. 1. Spreader of ZA - TS 3200 mineral fertilizers (a), process control sensors (b)

The spreader also has the ArgusTwin system, which ensures constant online monitoring and adjustment of the spreading system for optimal lateral distribution of fertilizers. This increases the efficiency of the fertilizer and is the basis for optimal crop management. The Argus system for determining the distribution areas is based on the registration of lateral fixation by radars (Fig.1b), which work regardless of the presence of dust and dirt and show excellent results in practice. ArgusTwin uses radars on both sides of the spreader to continuously monitor both the left and right spreader sections and, if necessary, automatically adjust the electrical spreader system independently of each other. [4-6]

With the TS spreader, working widths of up to $54 \mathrm{~m}$ and at the same time an ideal border spreading pattern are possible, for this a special ISOBUS spreader - ZA-TS is used, which belongs to absolutely high-performance spreaders. Every ISOBUS machine from 
„AMAZONE“ represents the state of the art for the digital future, with telematics [1], with almost unlimited possibilities. ISOBUS stands for a worldwide standard for communication between control terminals, tractors and implements on the one hand and farm office software on the other. From the wide range of technological possibilities of the ZA-TS mineral fertilizer spreader: border spreading system (yield-oriented spreading, border and shoulder spreading, ecologically oriented ditches, bed spreading with double-sided ridge shield) the possibility of differentiated fertilization [2].

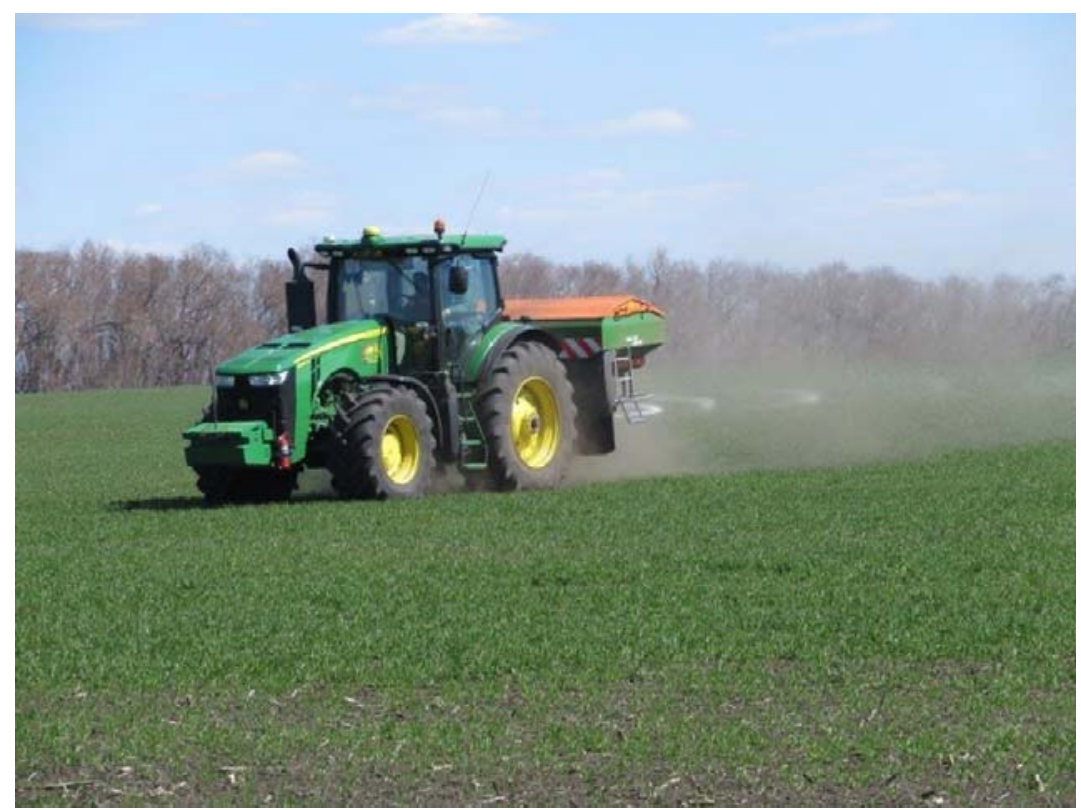

Fig. 2. Spreader of mineral fertilizers ZA-TS SamGAU in the fields of the Samara region.

This module allows for differential application - when feeding winter crops, it is easy to process application maps in the shape format. In this case, either the required values of the introduced material or the directly required amount of the active substance are set. This function is available as standard in AmaPad and can be ordered for AmaTron3 and Ama Tron4 with the GPS-Maps or GPS-Maps \& Doc software package. In honor of the 100th anniversary in 2019, the company presented the Samara State Agrarian University of SSAU with an innovative spreader of mineral fertilizers ZA-TS for research and development in the region. In the same year, the university tested a new spreader in one of the highly developed agricultural holdings in Samara on top dressing of winter crops, the "Yuka" variety (Fig. 2). [7-9] Two options were investigated: 1. Top dressing of winter crops in the tillering phase with ammonium nitrate with a rate of application of $150 \mathrm{~kg} / \mathrm{ha}$ in physical substance according to the generally accepted technology of uniform application over the entire area with conventional fertilizer spreaders - control; 2. Two-fold top dressing of winter crops based on the total amount of ammonium nitrate application, at a rate of 150 $\mathrm{kg} / \mathrm{ha}$ using the technology of differential application of mineral fertilizers - TS in two stages: in the tillering phase of winter wheat $-0-150 \mathrm{~kg} / \mathrm{ha}$ and in the phase tube exit $-0-60$ $\mathrm{kg} / \mathrm{ha}$. Before the current research, long-term space data on the fertility of the site where the research was carried out to calculate the effective rates of fertilization were studied. When harvesting with the definition of biological yield, the following results were obtained: according to the generally accepted technology of cultivation of winter crops with uniform fertilizing of crops throughout the field, $47.1 \mathrm{c} /$ ha was obtained, and with differentiated application $-53.5 \mathrm{c} / \mathrm{ha}$. That is, according to the new innovative technology 
with the use of the ZA-TS mineral fertilizer spreader, the yield of winter wheat increased by $13 \%$ with practically the same amount of fertilizers applied, which indicates a fairly high efficiency of the new technology when using the new "smart" machine.

Despite the increase in the application of mineral fertilizers in recent years, the outlined decline in soil fertility in the Russian Federation and in many countries of the world continues to grow, which requires the improvement of both the technologies for cultivation of agricultural crops - Mini-Till, Strip-Till, No-Till, and agricultural machines with mandatory further increase in the volume of application of various types and types of fertilizers [3]. At the same time, it is more efficient, according to the available scientific data and long-term joint research of the Samara State Agrarian University with the German company "Amazonen-Werke" to apply fertilizers intrasoil [3] with a corresponding improvement of working bodies and machines in general for soil cultivation and sowing with simultaneous introduction of both liquid and solid fertilizers. An example of such effective machines is the development of the "Amazonen-Werke" company, which presents the Russian agroindustrial complex with a unit with a large-volume $\left(4.2 \mathrm{~m}^{3}\right) \mathrm{X}$-Tender hopper and a cultivator with combined working bodies for longline fertilization - Cenius of various working widths depending on traction capabilities of power facilities - tractors. The fertilizer unit, depending on the power and weight of the tractor, is produced in the mounted version $-\mathrm{X}$-Tender and trailed - on the pneumatic drive - X-TenderT (Fig. 3) with the same volume $\left(4.2 \mathrm{~m}^{3}\right)$ hopper and pneumatic systems for transporting fertilizers to the workers bodies of tillage machines. Mineral fertilizers from the X-TenderT unit are supplied under pressure to the loosening working bodies of the Cenius cultivator and, with the help of a special device, switch over to work according to the following technological schemes: $1-100 \%$ of fertilizers are applied to the depth of soil cultivation by rippers; 2 $50 \%$ of fertilizers are applied to the depth of soil cultivation by rippers, and the other $50 \%-$ superficially, which significantly improves the operation of the tillage fertilizer.[10-12]

In addition, in the system of resource-saving technologies of the agroindustrial complex of the Russian Federation, soil cultivation machines with disc working bodies are widely used, after the passage of which the mulch layer required by agricultural technology is created. Disc harrows of the German company "AMAZONEN-WERKE" - "Catros" produced by JSC "Euotehnika" (Samara) and supplied to agricultural enterprises in Russia with a wide range of working widths in mounted and trailed versions with promising structural elements, also equipped with special equipment for fine processing soil with simultaneous application of mineral fertilizers when aggregated with a specialized large volumetric hopper for mineral fertilizers - X-TenderT [2].

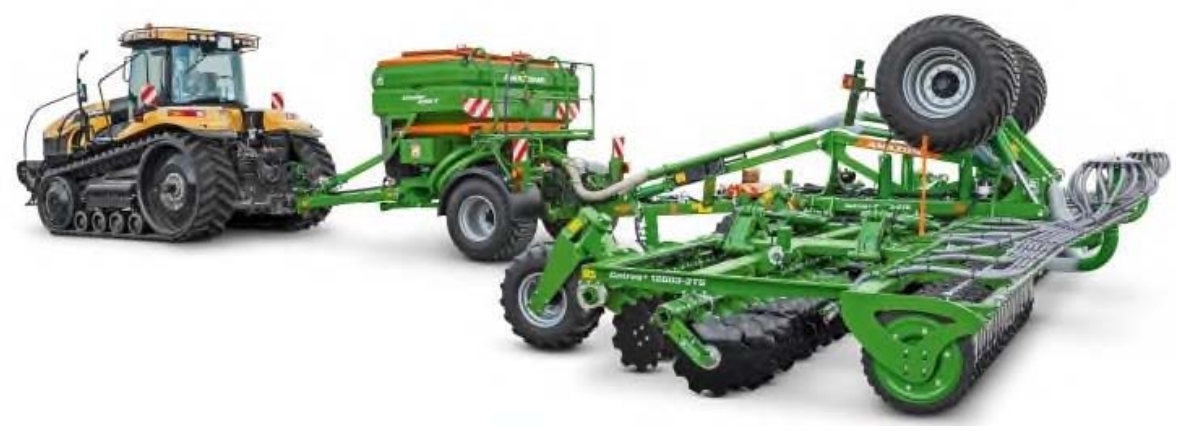

Fig. 3. Tillage and fertilizer unit: $\mathrm{X}-$ TenderT + Catros

In this variant, fertilizers are fed through the feed line from the X-Tender (T) unit to the working area of the Catros disc harrows, where they are mixed with the disc-treated soil, increasing its fertility due to the necessary nutrients with intensive growing of crops.[13-14] 


\section{Liquid fertilization methods}

The application of liquid mineral fertilizers (especially often KAS-32, KAS-32 + S, KAS$32+$ RPS) can be carried out using different technologies and various agricultural machines, depending on the timing and development phases of crops, the type of crops, the concentration of applied solutions according to active substance, application conditions (in strong winds and high atmospheric temperatures, etc.), etc. In Samara, the research used the technical means of JSC "Eurotechnika" (Samara, Russia) of the German agricultural machine-building company "Amazonen-Werke", which produces, along with a wide train of machines in terms of productivity, volumes of containers for solutions, technical and technological equipment, high-performance sprayers with their complete set necessary equipment, as well as highly efficient combined tillage and sowing fertilizing complexes for the following technologies:

1 - application of liquid mineral fertilizers during the growing season - with sprayers with coarse droplet nozzles (Fig. 4, I, III),

2 - application of liquid mineral fertilizers superficially to the soil in the root zone - with sprayers with extension hoses (Fig. 4.I, II.),

3 - application of liquid mineral fertilizers with the possibility of simultaneous application of solid mineral fertilizers locally to the root zone - with cultivators, injectors, plant feeders, combined tillage machines and seeders (Fig. 4.IV-V), which significantly expands the possibilities for the introduction of liquid fertilizers, since the limited application of liquid mineral fertilizers is currently associated mainly with an insufficient nomenclature and number of special agricultural machines for this, as well as the psychology of farmers due to insufficient research and awareness on this issue. Although developed and serially produced for the agroindustrial complex of Russia, special equipment and equipment for it for the introduction of liquid fertilizers ensures the effective use of liquid fertilizers according to various technologies, taking into account the biological characteristics of agricultural cultivation, the type of fertilizers, advanced methods of application both superficially and locally-subsoil. [15-18]

In this connection, systematizing the machines and equipment for the introduction of liquid fertilizers, the following technologies can be distinguished (Fig. 4):

I - with sprayers with multi-jet nozzles: 1 - onto the soil surface; 2 - onto the plant from plants and on the soil surface;

II - with sprayers with extension hoses to the soil surface;

III - with sprayers with extension hoses to the soil surface and plants;

IV - with universal unit FDC (JSC "Eurotechnika") for the working bodies of the cultivator Cenius during the main and pre-sowing soil cultivation;

$\mathrm{V}$ - with universal unit FDC when sowing grain crops under the anchor openers of the Primera DMC seeder and chisel openers of the Condor seeder, as well as when sowing row crops under the disc coulters of the precision seeder - EDX (all machines are produced in Russia - Samara, JSC "Eurotechnika"). 


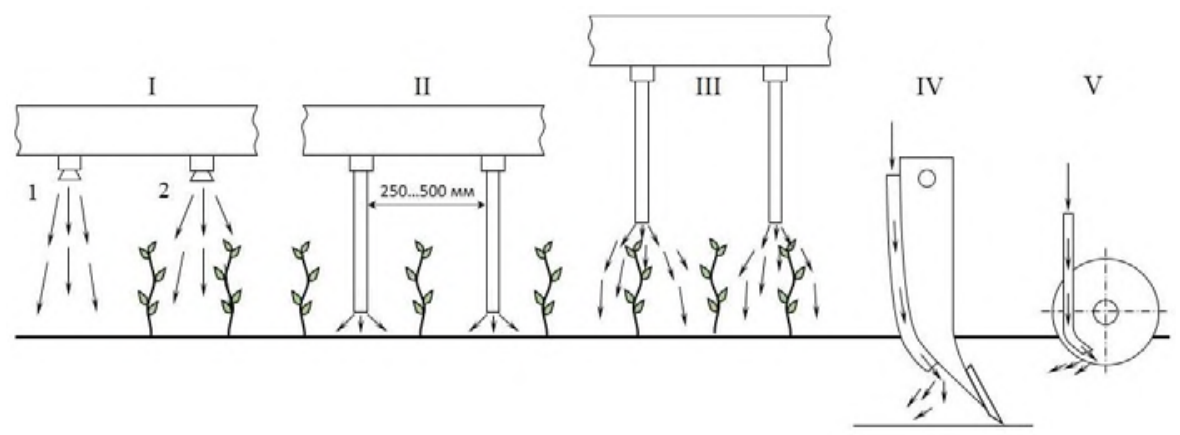

Fig. 4. Technical and technological schemes for the introduction of liquid mineral fertilizers

The technology of surface spraying of soil and plants with boom sprayers equipped with special nozzles fixed on the boom, used in experiments (Fig. 5);

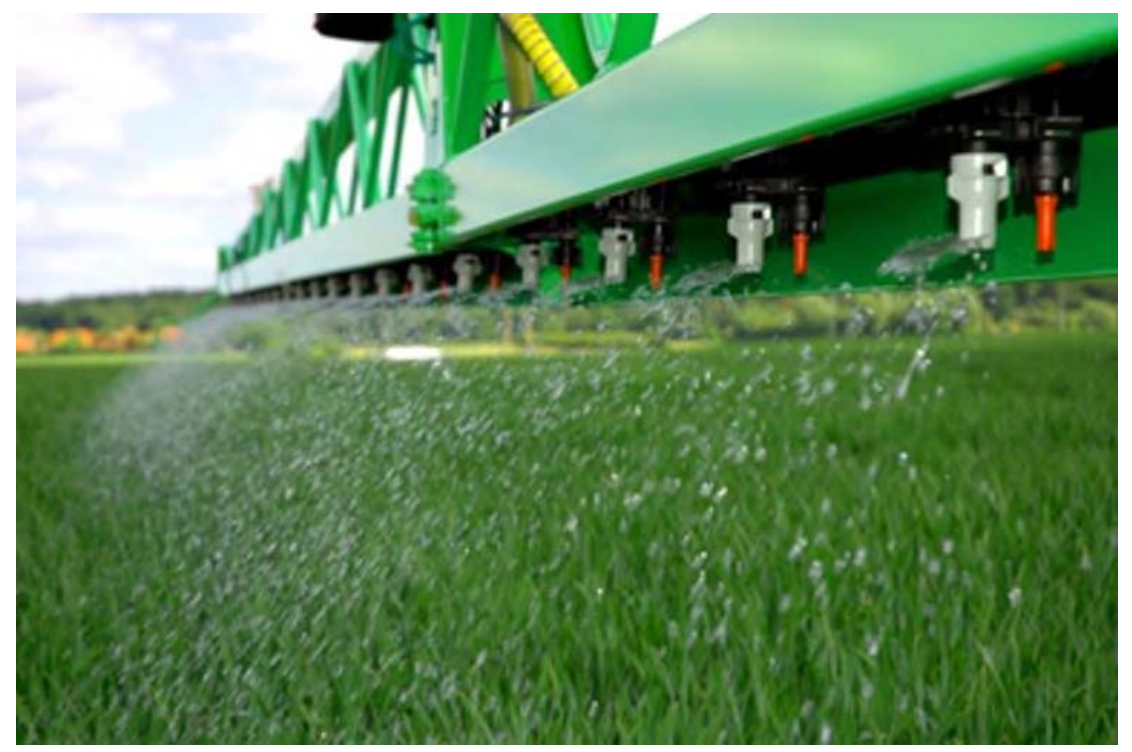

Fig. 5. Surface application of KAS by coarse droplet nozzles

The technology of fertilizing crops by spraying the soil surface with special extension cords - rubberized hoses with a sprayer at the end and a load - sprayers without restrictions in wind, soil irregularities, etc. In this case, the sprayer boom is installed at the level of the soil or - crops with a certain excess for a stable uniform application of liquid mineral fertilizers to the soil surface and - crops (Fig. 6). 


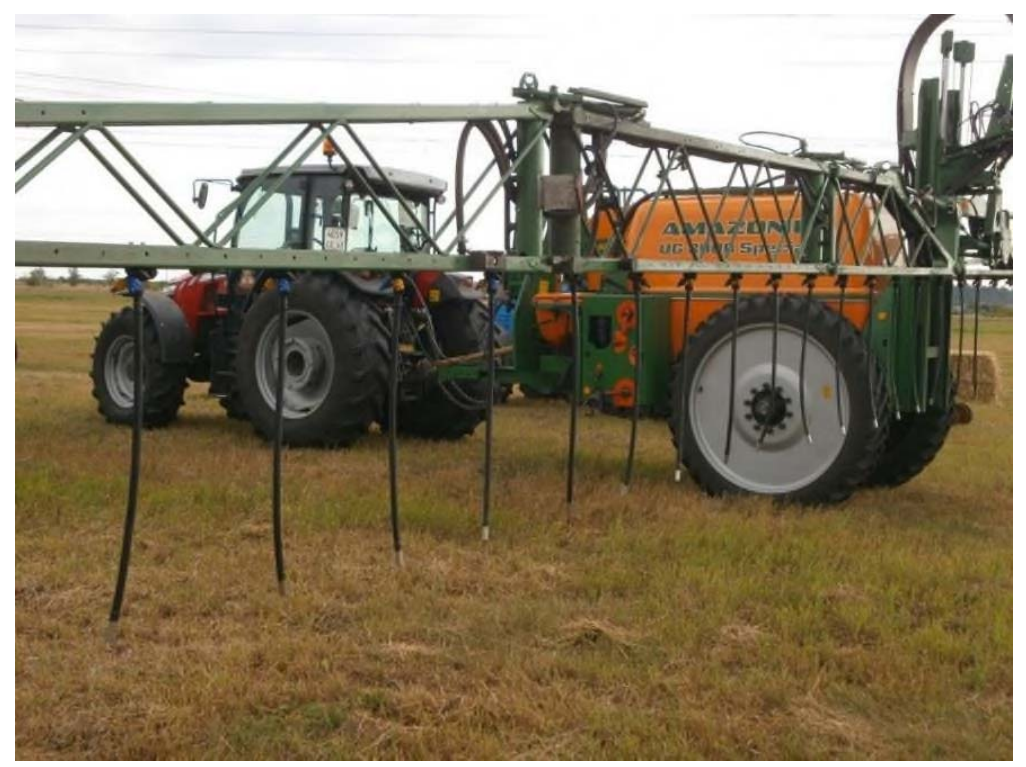

Fig. 6. Top dressing by a sprayer with extension rods

When crops are fertilized by surface weighting of liquid mineral fertilizers on the soil mainly tilled crops (corn, sunflower and others, not protected from "burns" with concentrated KAS-32), visible traces of KAS remain on the surface (Fig. 7).

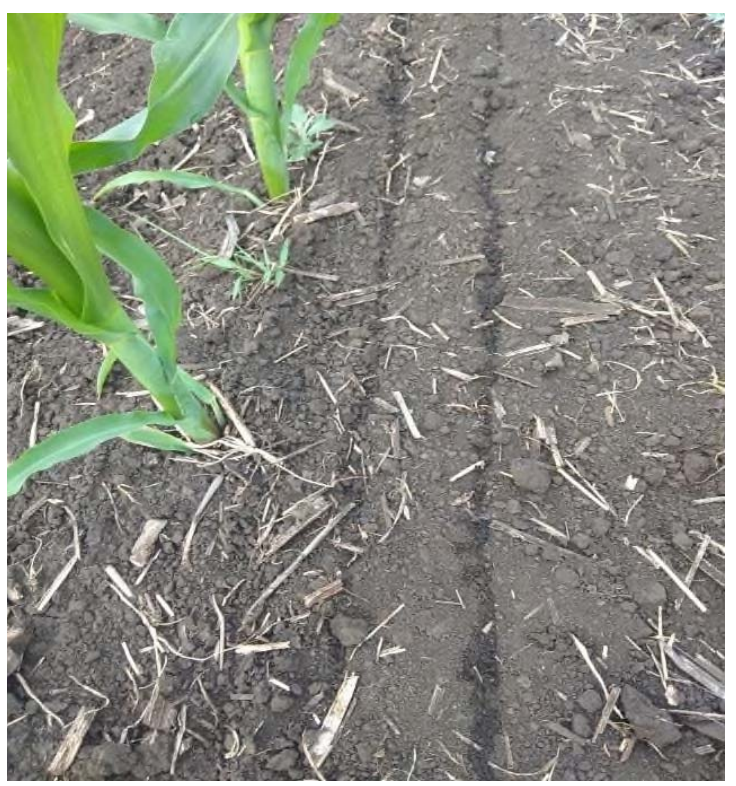

Fig. 7. Traces of KAS applied (twice in two passes) in the aisles of corn

Taking into account the growing interest of farmers in liquid mineral fertilizers for a number of their advantages in comparison with solid mineral fertilizers, the company JSC "Eurotechnika" has developed and manufactures a universal unit FDC 6000 for subsurface fertilization.

The "Amazonen-Werke" company, when solving the problem of applying liquid mineral fertilizers simultaneously with sowing, chose, in our opinion, the most effective 
design and technological scheme of use, newly created and manufactured in Russia (Samara) at JSC "Eurotechnika" unit FDC 6000 complete with grain and row-crop seeders, produced both in Germany - at the head enterprise "AMAZONE", and in Russia - at JSC "Eurotechnika". At the same time, seeders supplied to Russia and manufactured in Russia by "AMAZONE" at the request of Russian farmers are equipped with appropriate containers - bunkers for loading them with solid mineral fertilizers applied simultaneously with sowing. Thus, machine and tractor sowing complexes with the universal unit FDC 6000 for liquid fertilizers and seeders: row-crop EDX 9000-TC and grain DMC 9000, DMC 12000 c (Fig. 8), Condor 12000 and Condor 15000 receive significantly greater opportunities to create favorable conditions for agricultural seeds, sown with the simultaneous application of both solid and liquid mineral fertilizers, combining various basic elements $(\mathrm{N}, \mathrm{P}, \mathrm{K})$ and microelements in solid and liquid phases, which naturally contributes to the intensive development of agricultural crops with obtaining high yields with high quality. [19]

The unit consists of 2 tanks of 30001 each with a total volume of 60001 for liquid mineral fertilizers, an autonomous vane pump for filling the tanks with liquid mineral fertilizers, a working pump driven by a friction wheel, two tanks for clean water of 3001 each, lower links with a hitch for aggregating seeders with equipment for applying liquid mineral fertilizers, while the unit is operational at a working speed of up to $20 \mathrm{~km} / \mathrm{h}$ with possible application rates from 40 to $3001 /$ ha with a dosage accuracy of $+1 \%$ of the application rate, axles without brakes with pneumatic rubber wheels with a track width of $2.3 \mathrm{~m}$ and a drawbar consisting of a traction beam Kat. 2-5 and hitching eye.

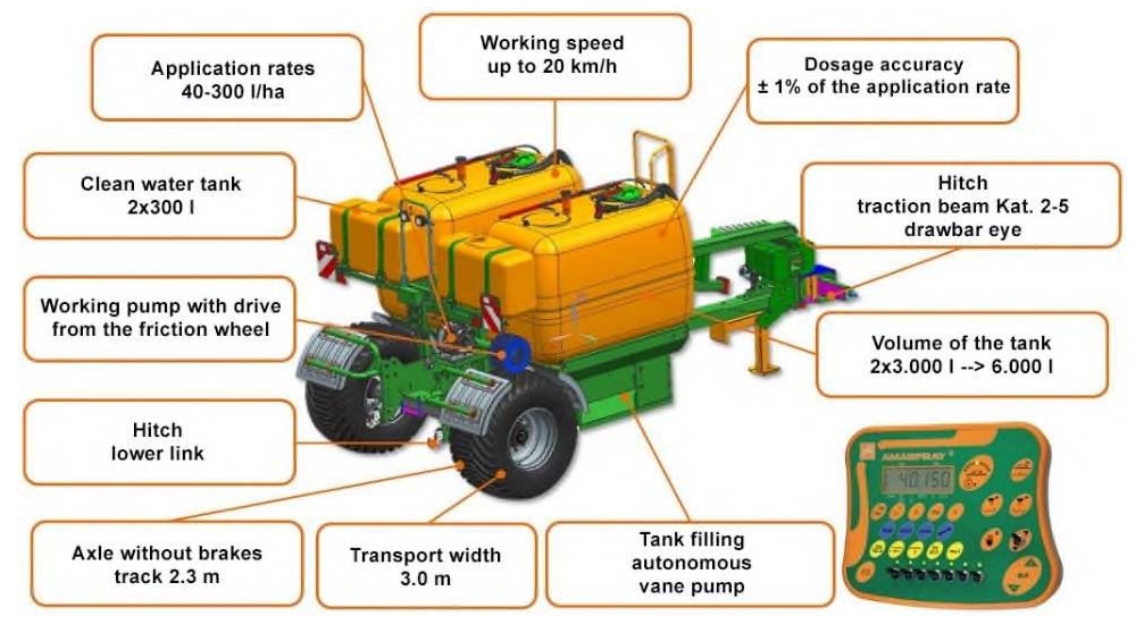

Fig. 8. Unit FDC 6000 for equipment of technological complexes - seeders of various types and purposes for the simultaneous introduction of liquid mineral fertilizers

The FDC 6000 can be used with various "Amazonen-Werke" seed drills for precision seeding of row crops (sunflowers, maize, soybeans, etc.) EDX 9000-TC (9 m working width), and for grain - high-performance seed drills for direct, mulch and conventional sowing DMC 9000 and DMC 12000 (working widths 9 and $12 \mathrm{~m}$ ) and high-performance seed drills also for direct mulching and conventional sowing Condor 12000 and Condor 15000 (working widths 12 and $15 \mathrm{~m}$ ) (Fig. 9, Fig. ten). In addition to the pulling power to move the seed drills, the FDC 6000 requires $50 \mathrm{hp}$ when fully charged [26]. 


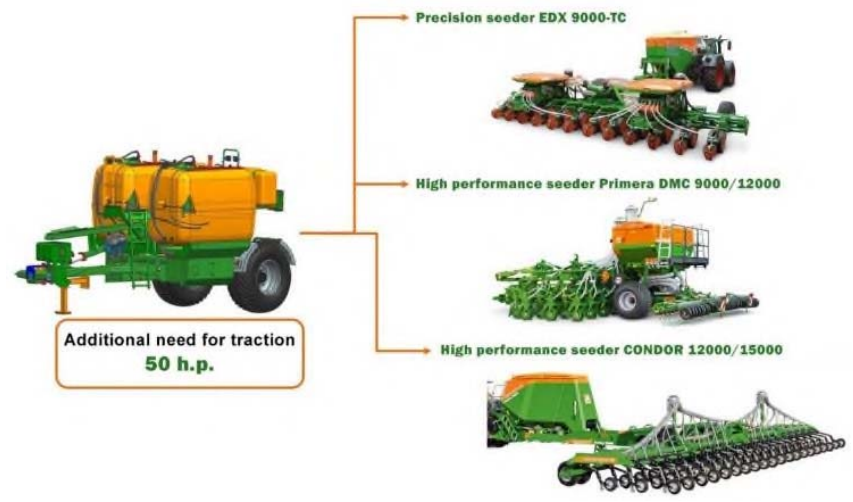

Fig. 9. Possible options for using the FDC 6000 unit with grain and row-crop seeders of the "Amazonen-Werke" company: EDX 9000-TC precision seed drill, grain seeders for classical technologies and No-Till, Mini-Till: DMC 9000; DMC 12000; Condor 12000; Condor 15000

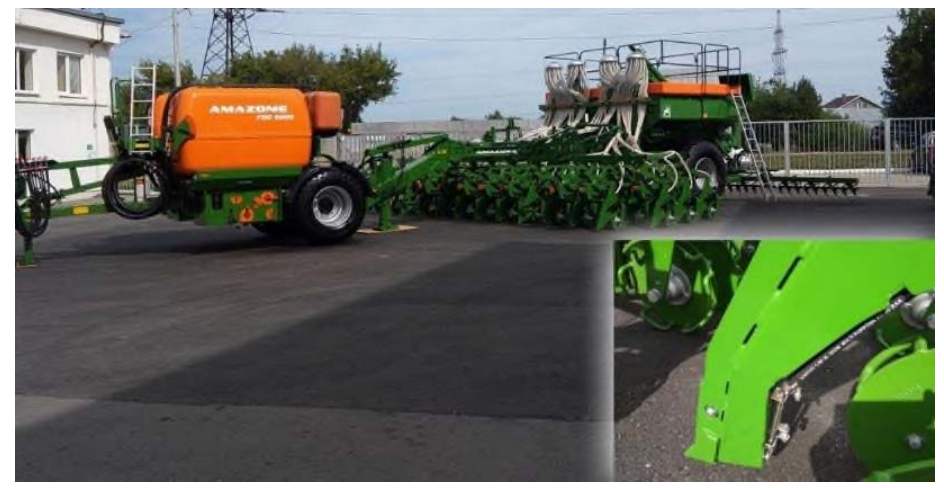

Fig. 10. Seeder DMC 9000 in unit with FDC 6000 and opener equipped with device for applying liquid mineral fertilizers

In $2018-2019$, on the fields of the Samara State Agrarian University together with KuibyshevAzot PJSC, the largest plant producing a wide range of mineral fertilizers, including in liquid form (KAS-32; KAS-24; KASSA (KAS with sulfur), RPS and etc.) with the use of mainly agricultural machinery of JSC "Eurotechnica" (Samara) of the German company "Amazonen-Werke" conducted research on the effectiveness of their use. There is a tendency for a significant increase in the yield and quality of products of such basic agricultural crops as winter wheat, durum spring wheat, soybeans, sunflower, grain corn [4].

The rates and doses of KAS application depend on the type of crops, the time and method of application, the predecessor and other factors. When applying KAS, it is necessary to use sprayers for coarse droplet application of liquid fertilizers [20].

To obtain maximum results from the use of KAS fertilizers, it is necessary to take into account all application factors, both favorable and unfavorable [21].

The best time for foliar top dressing with KAS solutions is morning (in the absence of dew) and evening hours. In cool and cloudy weather, this work can be done during the day. Plants should not be fed with KAS solutions at temperatures above $20{ }^{\circ} \mathrm{C}$, low relative humidity of less than $56 \%$, on a clear sunny day. Immediately after rains, strong dew, KAS cannot be used, since precipitation makes the structure of the upper leaf plate more permeable. Therefore, the treatment of crops should be carried out after the leaves of plants 
have dried. The optimal time of day for introducing KAS in a mixture with chemical plant protection agents is evening [4].

When applying liquid fertilizers KAS and KAS + sulfur, it is necessary to take into account their aggressive effect - burns of sunflower leaves, corn at any stage of development and grain crops when processing "spike" after the tillering phase with direct fertilization on the leaves.[22] In this connection, this technological operation with concentrated KAS must be carried out on grain crops in the "tillering" phase, after the "tillering" phase - on the "ear" with a solution of KAS 1/4-1/6, and on row crops - as root top dressing with special extenders on sprayers (Fig.) or coarse droplet nozzles of nonconcentrated KAS - as our studies have shown, the safe concentration of KAS-32, KAS$32+\mathrm{S}$, RPS is a solution of these drugs in a concentration of no more than $5 \%$ [4].

\section{Study location, soil and agroclimatic characteristics in the study season}

The research was carried out on the experimental field of the Samara State Agrarian University, which is located in the central zone of the Samara region, in the summer season 2018-2019.

Test plot soil - ordinary chernozem, residual carbonate, medium humus 4-6 (4.6), medium thick, heavy loamy with a content of easily hydrolyzable nitrogen with an average degree of supply $\mathrm{N}-41,0-50,0(48) \mathrm{mg} / \mathrm{kg}$, with a low content of total nitrogen $0.10-0.30$ (23)\%, with an average content of mobile phosphorus $\mathrm{P}-50-100(73) \mathrm{mg} / \mathrm{kg}$ и very high content of mobile potassium compounds $\mathrm{K}$ - more than 250 million, low content of mobile sulfur S 1-4 (0-6), pH the soil was equal to 5,0 - 8,0 $(7,4)$ units.

Before conducting research, in addition to calculations required to determine the optimal rates of application of mineral fertilizers, taking into account agrochemical recommendations, in 2018 and 2019, the soil was assessed by the quantitative composition of elements: N, P, R, S, Cu, Fe, Mn, Ph, organic matter-humus (3, Table 1., page 23,). [2223]

Research of the Samara State Agrarian University in 2018-2019 showed the advantages of applying liquid nitrogen sulfur-containing fertilizers in comparison with traditional solid ones - ammonium nitrate in sunflower cultivation [4].

Studies of the Barnaul State Agrarian University confirmed the efficiency of the FDC 6000 liquid fertilizer applicator developed by "AMAZONE" with various options for using seeders: Primera DMC, Condor and EDX in arid conditions of the Altai Territory. [24-25]

In some variants of experiments, the yield and economic effect were obtained for granular fertilizers, in other variants for liquid fertilizers [5].

This testifies to the expediency of continuing the experiments and revealing the advantages of options and technologies for applying both granular and liquid fertilizers, depending on the weather conditions and climatic conditions of the Altai subzones.

\section{Conclusions}

1. The tasks of increasing the volume of crop production - grain, solved by the agroindustrial complex of Russia, are accompanied by an increase in the volume of applied fertilizers of various types (liquid, solid) and using different technologies, which significantly increases the yield and quality of agricultural products with a decrease in its cost.

2. Agricultural engineering enterprises in the Russian Federation, producing along with widespread machines for applying granular fertilizers, improve their designs, develop new 
efficient machines for applying liquid fertilizers and identify rational combinations of using various machines and technologies for applying fertilizers, which is demonstrated in their innovative developments and deliveries to the agroindustrial complex of Russia, the leading enterprise for trailers - JSC "Eurotechnika" (Samara) of the German company "AmazonenWerke".

3. It is advisable to continue more extensive experiments to identify rational efficient technologies and a set of machines for applying both granular and liquid fertilizers, depending on the weather and climatic conditions of the zones of Russia, for issuing recommendations to agricultural enterprises by zones.

\section{References}

1. Yu. A. Ivanov, V. I. Pakhomov, S. I. Kambulov, D. V. Rudoi, (ICMTMTE 2018) Cep. MATEC Web of Conferences, 224, $05023 \quad$ (2018) https://doi.org/10.1051/matecconf/201822405023

2. A. Altybayev, A. Zhanbyrbayev, B. Meskhi, D. Rudoy, A. Olshevskaya, A. Prohorova, $\begin{array}{lllll}\text { E3S Web of } & \text { Conferences, } & \text { 135, }\end{array}$ (2019)https://doi.org/10.1051/e3sconf/201913501078

3. B. Meskhi, B. Golev, V. Efros, D. Rudoy, A. Olshevskaya, V. Zhurba, Y. Chayka, E3S Web of Conferences, 135, $01083 \quad$ (2019) ITESE-2019 https://doi.org/10.1051/e3sconf/201913501083

4. J. Gerber, A. Zavaly, A. Gavrilov, A. Olshevskaya, N. Kiyan, IOP Conf. Series: Earth and Environmental Science, 012014 IOP Publishing, 403 (2019) doi:10.1088/17551315/403/1/012014

5. A. A. Korotky, E. V. Marchenko, S. I. Popov, Ju. V. Marchenko, N. S. Dontsov, Theoretical foundations of modeling the process of transport vehicles steel ropes structural defects formation, XIII International Scientific and Practical Conference «State and Prospects for the Development of Agribusiness - INTERAGROMASH 2020»: E3S Web of Conferences, 175, $05018 \quad$ (2020) doi.org/10.1051/e3sconf/202017505018

6. G. Parkhomenko, S. Kambulov, A. Olshevskaya, A. Babadzhanyan, N. Gucheva, I. Mekhantseva, IOP Conf. Series: Earth and Environmental Science, IOP Publishing, 403, 012144 (2019) doi:10.1088/1755-1315/403/1/012144

7. Y. Lachuga, A. Soloviev, A. Matrosov, I. Panfilov, V. Pakhomov, D. Rudoy, IOP Conf. Series: Earth and Environmental Science, IOP Publishing, 403, 012055 (2019) doi:10.1088/1755-1315/403/1/012055

8. A. A. Korotky, S. I. Popov, G. A. Galchenko, Ju. V. Marchenko, D. S. Drozdov, The use of SmartBox container for agrobusiness logistic processes optimization, XIII International Scientific and Practical Conference "State and Prospects for the Development of Agribusiness - INTERAGROMASH 2020»: E3S Web of Conferences, 175, 13019 (2020) doi.org/10.1051/e3sconf/202017513019

9. V. V. Ivanov, S. I. Popov, E. M. Selemeneva, N. T. Babazhanov, Study of technological characteristics of the process of formation of vibration mechanochemical oxide coating, XV International scientific-technical conference «Dynamics of technical systems» (DTS-2019): AIP Conference Proceedings, 2188, 020015 (2019) doi.org/10.1063/1.5138389

10. V. Zhurba, Y. Chayka, N. Gucheva, D. Ushakov, N. Ugrekhelidze, N. Kulikova, M. Egyan, E3S Web of Conferences, 135, 01087 (2019) ITESE-2019 https://doi.org/10.1051/e3sconf/201913501087 
11. A. Zavaliy, S. Volozhaninov, O. Shiian1, D. Rudoy, A. Olshevskaya, E3S Web of Conferences, INTERAGROMASH, 175, $05003 \quad$ (2020) https://doi.org/10.1051/e3sconf/202017505003

12. V. V. Ivanov, S. I. Popov, A. V. Kirichek, Investigation of optimal chemical composition of cast aluminum alloys for vibrational mechanical-chemical polishing and deposition of protective and decorative coatings, XI International Conference on Mechanical Engineering, Automation and Control Systems (MEACS 2017): IOP Conference Series: Materials Science and Engineering, 327, 032026 (2018) doi:10.1088/1757-899X/327/3/032026

13. V. V. Ivanov, S. I. Popov, A. V. Kirichek, Qualitative Characteristics of MoS2 SolidLubricant Coating Formed by Vibro-Wave Impact of Free-Moving Indenters, Key Engineering Materials, 736, 18-22 (2017) DOI:10.4028/ www.scientific.net/ KEM.736.18

14. E. Sokolova, V. Orobets, O. Sevostyanova, E. Gorchakov, D. Rudoy, A. Olshevskaya, A. Babajanyan, E3S Web of Conferences, INTERAGROMASH, 175, 03015 (2020) https://doi.org/10.1051/e3sconf/202017503015

15. M. Mazanko, E. Prazdnova, D. Rudoy, A. Ermakov, A. Olshevskaya, T. Maltseva, E3S Web of Conferences, INTERAGROMASH, 175, $01010 \quad$ (2020) https://doi.org/10.1051/e3sconf/202017501010

16. A. Altybayev, Y. Naydenko, B. Meskhi, A. Mozgovoy, D. Rudoy, A. Olshevskaya, E3S Web of Conferences, INTERAGROMASH, 175, $03019 \quad$ (2020) https://doi.org/10.1051/e3sconf/202017503019

17. I. Boukhanef, A. Khadzhidi, L. Kravchenko, Z. Ayoub, K. Abdennour, E3S Web of Conferences, INTERAGROMASH, 175, 12002 https://doi.org/10.1051/e3sconf/202017512002

(2020)

18. V. Chernovolov, L. Kravchenko, A. Nikitina, V. Litvinov, E3S Web of Conferences, INTERAGROMASH,

175 , 05016

(2020) https://doi.org/10.1051/e3sconf/202017505016

19. V. Kravchenko, L. Kravchenko, V. Oberemok, E3S Web of Conferences, INTERAGROMASH, $\quad \mathbf{1 7 5}, \quad 05017$ https://doi.org/10.1051/e3sconf/202017505017

20. A. Nesmiyan, L. Kravchenko, V. Khizhnyak, E. Zubrilina, E3S Web of Conferences, INTERAGROMASH,

175 , 05019

(2020) 2020 https://doi.org/10.1051/e3sconf/202017505019

21. Y. Chayka, et al., E3S Web of Conferences, INTERAGROMASH, 175, 09007 (2020) doi: $10.1051 / \mathrm{e} 3$ sconf/202017509007

22. W. Strielkowski, et al., Energies, 12(7), 1392 (2019). doi: 10.3390/en12071392

23. S. Nukeshev, I. Mamyrbaeva, A. Balabekova, Z. Zhaksylykova, K. Eskhozhin, Journal of Engineering and Applied Sciences, 13(1), 130-136 (2018)

24. A. M. Petrov, M. A. Kanaev, Yu. A. Savelev, S. A. Vasilev, E. S. Kanaeva, Research Journal of Pharmaceutical, Biological and Chemical Sciences, 9(5), 925-934 (2018)

25. A. V. Dichenskiy, N. V. Gritz, Innovative in Agriculture. Collection papers of the XI international scientific and practical conference, 21-25 (2019)

26. S. V. Teplyakova, A. A. Kotesova, S. I. Popov, A. A. Kotesov, The transition from the sample data to the total aggregate of the final volume and the analysis of this transition laws, International Scientific Conference "Construction and Architecture: Theory and Practice for the innovation Development» (CATPID-2020): IOP 
Conference Series: Materials Science and Engineering, 913, 042054 (2020) doi:10.1088/1757-899X/913/4/042054 